\title{
Evaluation of Nutritional Habits of Obese Children in Toddler Period and Their Families*
}

\author{
Senay Cetinkaya ${ }^{1 \#}$, Ayse Gurol ${ }^{2}$ \\ ${ }^{1}$ Faculty of Health Sciences, Department of Nursing, Child Health and Nursing, Çukurova University, Adana, Turkey \\ ${ }^{2}$ Atatürk University, Health Services Vocational School, Erzurum, Turkey \\ Email: senayg_202@hotmail.com, "scetinkaya@cu.edu.tr
}

How to cite this paper: Cetinkaya, S. and Gurol, A. (2018) Evaluation of Nutritional Habits of Obese Children in Toddler Period and Their Families. Open Journal of Pediatrics, 8, 158-177.

https://doi.org/10.4236/ojped.2018.82019

Received: January 22, 2018

Accepted: June 18, 2018

Published: June 21, 2018

Copyright () 2018 by authors and Scientific Research Publishing Inc. This work is licensed under the Creative Commons Attribution International License (CC BY 4.0).

http://creativecommons.org/licenses/by/4.0/

\begin{abstract}
Toddler period is the period that nutritional habits are learnt. This research is a semi-analytical field research that was performed in doctors' offices 1, 6 and 7 in the provincial center of Konya with the purpose of determining the socio-demographic characteristics of obese pre-school children and their families who volunteered to participate in the research. The cosmos of the research consists of 22 village clinics in Konya provincial center. Obese Cosmos consists of obese children between 1 - 3 years of age and their families who applied to outpatient clinics of the Doctors' Offices numbered 1, 6 and 7, which were selected with cluster sampling method, for vaccination and who accepted to participate in the research. Data were collected between 01 January 2005 and 31 March 2005 by using a questionnaire and a form of anthropometric measures to enter the measures of height, weight, thickness of skin folds, and waist and hip size. The difference between the increase of weight of the mother during pregnancy and the non-categorized RW outputs of the child in birth was found to be statistically significant $(\mathrm{p}<0.05)$. Variation analysis was performed in order to check whether or not there was a difference between the period of breastfeeding and Standart Deviation Score (SDS) and Relative Weight $(\mathrm{RW})$ values and it was found to be significant $(\mathrm{p}<0.05)$. No statically significant relationship was found between the time child spends watching TV daily and SDS and RW values of the child $(p>0.05)$. Although there was found no statically significant relationship between the daily play hours of the child and SDS ( $p>0.05)$, there was a significant relationship between RW ( $p$ $<0.05$ ). It is important that the parents should spend more time playing with their children and increasing the play time. Informing booklets have been prepared and given to parents with the purpose of training.
\end{abstract}

${ }^{*}$ This study has been presented as poster report in 42th Turkish Pediatrics Congress (15-20 May 2006, Antalya-Turkey). This article was the post graduate thesis, the academic consultancy of which was carried out by Senay Cetinkaya. Financial support for this study has been provided from Selçuk University Research Fund numbered 04/054. A part of it was published in Turkish in Atatürk Üniversitesi Hemşirelik Yüksekokulu Dergisi Temmuz-Eyü, 2008; 11(3): 59-69. 


\section{Keywords}

Toddlers, Obesity, Nutrition, Relative Weight, Standard Deviation Score

\section{Introduction}

Obesity is an important health problem that may result in social, psychological and serious medical problems arising from increasing of fat structure in cases where the energy intake exceeds energy spent [1] [2].

Number of overweight children and adolescents and the prevalence of obesity have increased in all over the world [3]. According to various researches having been done in Turkey, it has been found that obesity prevalence in children ranges from $1.9 \%$ to $30.7 \%$ [4] [5] [6].

Obesity is a chronic sickness with an increasing prevalence in both developed and developing countries, affecting children as well as adults [7]. With the focusing of researches on obesity and health problems, it has been reported that obesity prevalence in toddlers has increased as compared to 30 years ago and $30 \%$ of fat children turn to fat adults [8]. Therefore defining obesity in toddlers is crucially important to prevent complications related to obesity adulthood [9].

The first environment about toddler obesity is the environment of family. The obesity of the family, its socio-economical status, educational status and family type are all related to toddler obesity. The activity of the family prevents the child from being obese [10]. Mothers need to undertake an important role in order to avoid obesity of children in pre-school period, since mothers have an important part in sharing the activities and diets with their children [11]. Pediatrics nurses work in first level and for this reason they take part in curing obesity [12].

Treatment of childhood obesity is difficult; it is a disease with both physical and emotional aspects. Furthermore, it is a high possibility that obese children may turn to be obese adults and this disease may end in other illnesses and even death. Therefore taking measures in advance may save lives [11].

The period of 1 - 3 years is a time when walking, running, speaking, nutrition habits and toilet training habits are gained [13]. Starting from the first year of life, the child grows to gain his/her independence; she/he turns out to be a member of the family that has started to change. In this period of developing and changing, the nutritional habits of the child directly or indirectly are affected by the nutritional habits of the family, particularly those of the parents. For this reason, the child should be led to eating different kinds of dishes so as to help him/her to acquire a certain habit of choosing the right food that extends to forwarding ages. Healthy nutrition advices can be directed for the whole family; however, need for special kinds of nutrition of small children should be taken into consideration [14].

\section{Methods}

This research is a semi-supplemental analytic area research that has been done 
with the aim of indication the nutrition habits of obese children and their families' socio-demographic features in toddler period that have been volunteered to join the research in village clinics numbered 1, 6 and 7 in Konya provincial center. These health centers were selected because they included families from Konya province center and different socio-economic level. Konya is in Central Anatolia Region of Turkey located in $37^{\circ} 52^{\prime}$ east and $32^{\circ} 30^{\prime}$ north.

Twenty-two doctors' offices in Konya provincial center in 2005 have constituted the cosmos of the research. Twenty-two village clinics in Konya provincial center were divided into layers as "lower, intermediary and upper socio-economical layers" after the interviews with the Provincial Directorate of Health. By making a list of the doctors' offices in each layer, via a simple random sampling method, a cluster (doctors' office) was selected representing each socio-economical level. According to this choice, doctors' offices with the numbers of 1,6 and 7 have constituted the research examples.

The entire portion of obese children (children with weight exceeding 95 percentile according to their age) who have applied for revaccination or physical examination in the outpatient clinic of the doctors' offices and their parents who have volunteered to take part in this research were selected with no-probability sampling method for the sampling of the research between 01 January 2005 and 31 March 2005. Verbal approval was obtained from the parents participating in the research and from the institutions that the research was implemented in.

Questionnaires and measurement methods were used for the collection of data. Anthropometric measurements and general information about the children, and a questionnaire about the nutritional habits of the parents of the children were used. Anthropometric measurements and the questionnaire were prepared by making use of the literature [7] [15] [16] [17] [18] [19]. Total seventy-six questions were involved, 11 in the form for anthropometric measurements consists of 11 questions, and 65 in the questionnaire regarding the general information and nutritional habits of the parents of the children. A preliminary application was applied to 10 mothers with obese children in toddler period.

Data of the research were obtained by face-to-face interviews with the parents of obese children between the ages of $1-3$, and collected by the method of measuring height-weight, SDS and RW values, thickness of the skin folds, and waist/hip ratio of the children.

The height-weight values, SDS, RW values, thickness of the skin folds, and waist/hip rates of the obese children between the ages of $1-3$ are the dependant variables of the research. The independent variables of the research are child's being in toddler period, the educational level of the parents, their profession, body mass index (BMI), the age, gender, number of meals per day, the preferred food groups, the starting time of additional foods and the habits of snacking of the child.

Weight measurement is done with the same electronic portable scale which is sensitive to $100 \mathrm{~g}$, taking the calibration of measurement tool into consideration. Height measurement of the children younger than 2 years of age was taken with 
the children are lying, and of children older than 2 years of age when standing, with a special measurement tool, one side is stationary and other is moving. During the height measurement, care was taken that heel, gluteus and occipital process were in the same line. Measurements were repeated 3 times for each child. Measurements were taken with children dressed and without shoes. Children's height and weight were compared with the norms of US National Center for Health Statistics (NCHS).

In clinical evaluation, the following were used as obesity criteria: $>95$ percentile values according to weight, thickness of skin folds $>95$ according to the tables, and waist/hip ratio $>0.8$ in girls, and $>1.0$ in boys [7] [8] [20].

The waist measurement was taken as the narrowest caliper between the ribs and spina iliaca anterior superior and hip measurement was taken as the largest caliper passing over from the most prominent part on gluteus maximus muscles at the back and over symphyisis pubis at the front. The waist $(\mathrm{cm}) / \mathrm{hip}(\mathrm{cm})$ ratio for the children was calculated. This ratio should not exceed 0.8 for females and 1.0 for males. The values over these figures are signs of increasing health risks [7] [21]. The average value for children is accepted as 0.85 [20].

The measurement for thickness of the skin folds was taken using a skinfold caliper tool on the region between the shoulder and elbow on the posterior of triceps muscle. 3 measurements were taken and their average was calculated. According to NCHS Triceps skin fold thickness reference values, 85 percentile is defined as overweight, and over 95 percentile is defined as obesity [2] [10] [16] [20] [22] [23].

The following formula was used in $Z$ score calculation;

$$
Z=\frac{x-x \text { (ort.) }}{S}
$$

Here, $x=$ measured value, $\mathrm{x}$ (average) $=$ average value obtained from reference population, and $s=$ Standard deviation of reference population. SDS value over $+2 \mathrm{SD}$ in children with weight complies with the average according to their age is defined as obesity [24].

The following formula was used in calculation of Relative Weight (RW) value;

$$
\mathrm{RW}=\frac{\text { Weight of Child } \times 100}{\text { Ideal weight }}
$$

Relative weight between $110 \%$ and $120 \%$ is accepted as overweight, and if over $120 \%$, as obesity [2] [23] [24] [25] [26].

In the research, data obtained from the questionnaire and measurements for each child was entered in a PC. SDS, RW, waist/hip ratios were calculated. Data obtained were summarized as average \pm standard deviation. Research data were evaluated using a statistics package program (SPSS for Windows 10.0) on PC. Chi-square, One Way Anova and independent inter-group $t$ test were used when examining the distribution of children in the sampling group and their parents according to descriptive features and factors that affect children's obesity; have been used. P values smaller than 0.05 have been accepted as statically significant. 
Awareness of the parents must be increased about nutritional habits as regards the factors effective in the development of obesity in toddler period. An informative booklet was prepared by making use of the literature for toddler obesity and this booklet is given to mothers [12] [14] [19] [21] [27]-[32].

For this survey financial support was supplied by Selçuk University Survey Fund with No: 04/054.

\section{Terms and Abbreviations}

Obesity: Obesity is accepted as BMI 95 and over according to tables defined for age and gender [2] [23] [33].

Being overweight: Being overweight is accepted that BMI is between 85 and 95 percentile according to tables defined for age and gender [2] [23] [33].

SDS: This is a term that explains deviation level of the individual's measured parameter from the normal value in the society. The term " $Z$-score" is also used for deviation from the mid value or standard deviation score (SDS, SSS) [24].

RW: Weight according to height is a commonly used criterion in diagnosing obesity in children [2].

BMI: Body Mass Index is obtained by dividing weight in kilograms by square meters of height, and it is the method used in diagnosing obesity [2].

\section{Results and Discussion}

\subsection{Discussion}

\section{1) Socio-demographic features of the parents of the child}

The researches have shown that socio-economical and cultural status and demographic structure of the parents are indicative in constituting the nutritional behaviors of the child. The children of the parents with high socio-economical status gain weight as a result of over-nutrition, whereas the children of the parents with lower socio-economical status gain weight as a result of unbalanced nutrition [34].

Twenty-nine $(58 \%)$ of the parents included in the study are in intermediary status whereas 21 (42\%) of them are in high socio-economical status. Twenty-nine (54\%) of the families are core families, 21 (42\%) of them are larger families, and $2(4 \%)$ of them are separated. According to the study of Dündar and colleagues (2000) on 2148 children between 6 and 17 years of age, obesity was found in $12 \%$ of the students. The frequency of obesity was found to be higher in the private college the research was performed as compared to the children of parents with lower socio-economical status [35]. In the work of Aktaş (2001), the rate of obesity prevalence in girls and boys in middle socio-economical status has been defined as higher [17]. On considering the fact that parents of 1 - 3 age group with middle socio-economical status are in majority in such a developing country, the similarities are striking.

Thirty-seven (74\%) of the parents live in the city center. Thirty-seven (74\%) of the parents live in apartments, and $13(26 \%)$ of them live in detached-houses. 
When the number of members of families are considered, it seen that $14(28 \%)$ of them have 3 members, $10(20 \%)$ have 4 members, 5 (10\%) have 5 , and 5 (10\%) have 6 members. The number of the families with 7 and more members is $16(32 \%)$.

On looking at the number of children in the family, 18 (36\%) of them have 2 children, $16(32 \%)$ of them have 1 child, $14(28 \%)$ of have 3 , and 1 (2\%) of has 4 children, whereas the number of the families with more than 5 children is 1 (2\%).

Twenty (40\%) of mothers are between 19 and 24 years of age, 19 (38\%) are between 25 and 30, and 11 (22\%) are between 31 and 36 years of age. Nineteen (38\%) of the fathers are between 28 and 32, 16 (32\%) are between 23 and 27, 11 (22\%) are between 33 and 37, and 4 (8\%) are between 38 and 42 years of age.

Twenty-five $(50 \%)$ of the mothers are in the education level of primary school/literacy, 16 (32\%) of them are graduates of high school, 7 (14\%) of them are graduates of higher education schools, and $2(4 \%)$ of them are graduates of license and postgraduate programs, whereas $20(40 \%)$ of the fathers are in the education level of primary school/literacy, 13 (26\%) of them are graduates of higher education schools, $11(22 \%)$ of them are graduates of high school, and 6 $(12 \%)$ of them are graduates of license and postgraduate programs. Increasing the education level of mothers is rather important. Thirty-four (68\%) of the mothers are housewives, $11(22 \%)$ of them have been retired workers or civil servants, and 5 (10\%) of them are self employed. Twenty-seven (54\%) of the fathers are retired workers or civil servant, 20 (40\%) of them are self employed, and $3(6 \%)$ of them are farmers.

Parental obesity is the most important risk factor for toddler period obesity. Familial effects are related to genetic factors, life style and nutritional habits of the parents [18].

Two (4\%) of the mothers have $20<$ thin BMI, 22 (44\%) of them have $20-24$ normal BMI, 24 (48\%) of them have 25 - 29 slightly fat BMI, 2 (4\%) of them have 30 - 39 obese BMI whereas 1 (2\%) of the fathers have $20<$ thin BMI, 7 (14\%) of them have 20 - 24 normal BMI, 37 (74\%) of them have 25 - 29 slightly fat BMI, 5 (10\%) of them have 30 - 39 obese BMI. As seen, slightly obese parental BMI is rather significant.

It has been found that the possibility of finding obese individuals in the parents of obese individuals is higher. In the study Fogelholm and colleagues have performed (1999) on 201 children, it has been found that the parents who have obese children have higher BMIs than the parents who have normal weighted children [36].

\section{2) Findings of the children}

Twenty-eight (56\%) of the children included in the study are boys, and 22 $(44 \%)$ of them are girls. No prominent differences related to gender have been reported in literature of the studies on obesity and including the entire childhood period. According to studies involving adolescence and pre-adolescence 
periods however, it has been emphasized that obesity prevalence in girls are higher [37].

Seventeen (34\%) of the children are in their 20 - 25 months, $16(32 \%)$ of them are in 32 - 36 months, 15 (30\%) of them are in $14-19$, and $2(4 \%)$ of them are $26-31$ months of age. Seven (14\%) of the children are twins or triplets, and 7 (14\%) of them are adopted children. While twenty-two (44\%) the children included in the study are the first child of their parents, 17 (34\%) of them are second, and $9(18 \%)$ of them are third children; the number of the children that are the 4 th or after 4 th children of their family is $2(4 \%)$. While $12(24 \%)$ of the children have a diagnosed illness, $8(16 \%)$ of them go to kindergarten.

Table 1 shows the anthropometric measures of the children included in the study.

It has been found that $31(72.09 \%)$ of the mothers did not smoke during their pregnancy, 26 (\%60.46) of them did not have any sickness, 24 (55.82\%) of them did have good nutrition, 24 (55.82\%) of them did not experience morning sickness much, and 17 (39.54\%) of them had a good appetite. As these findings are related to the pregnancy period of the mothers ( 7 children are adopted) numbers and percentages are different. On looking at the weight situation of mother during their pregnancy, it has been found that 1 (2.32\%) of them gained 7 kilograms or less during pregnancy, 15 (34.89\%) of them gained 11 - 13 kilograms, and 19 (44.18\%) of them gained 14 or more.

It has been indicated that over-feeding and increase of the birth weight in the last trimester of pregnancy contribute to the risk of obesity [38]. It has been indicated in some studies that the risk of developing of obesity in the childhood and adolescent periods is greater for babies with big birth weights. It has been found in this study that $39(78 \%)$ of the children in research were term babies, 22 (44\%) of them were born with a birth weight of $3.6-4.5 \mathrm{~kg}, 17(34 \%)$ of them were born with $2.6-3.5 \mathrm{~kg}$, and $3(6 \%)$ of them had birth weights $2.5 \mathrm{~kg}$ or lower; $1(2 \%)$ of them was in the group of $4.6 \mathrm{~kg}$ or more. In the study of Darcan and colleagues (2000) on 108 cases that were diagnosed as exogenous obesity, it was found that the average birth weight in the obese group was $3.57 \pm 0.75 \mathrm{~kg}$ [39]. In this study, the fact that majority of the children are between $3.6-4.5 \mathrm{~kg}$

Table 1. Arithmetic average (X) and Standard Deviation values (SD) of obese children.

\begin{tabular}{cc}
\hline Anthropometric Measuring & $\mathrm{X} \pm \mathrm{SD}$ \\
\hline Age (month) & $25.40 \pm 7.65$ \\
Height (cm) & $92.82 \pm 7.41$ \\
Weight $(\mathrm{kg})$ & $15.50 \pm 2.43$ \\
Waist/Hip ratio & $0.99 \pm 2.82$ \\
Triceps skin fold thickness (mm) & $16.18 \pm 2.57$ \\
SDS & $2.06 \pm 0.95$ \\
Relative weight (\%) & $113.86 \pm 8.18$ \\
\hline
\end{tabular}


(44\%) shows similarity to that study.

It has been found that $16(32 \%)$ of the mothers worked after pregnancy, and $34(68 \%)$ of them did not. When asked to the working mothers that who looked after the baby, 9 (56.25\%) of them answered as the grandmother, and 7 (43.75\%) of them answered as the baby sitter. On examining the current working status of mothers, it has been found out that 16 (32\%) of them are working and 7 (43.75\%) of those working mothers let their baby be taken care of by their grandmother. This data is important as regards the training to be given to the person taking of the baby.

\section{3) Findings related to nutrition of the child}

The nutritional habit of child in toddler period determines the nutritional habits in later ages. Protective effect of breastfeeding against obesity is known well [2]. Bottle-feeding the baby whenever it cries, early starting of giving high calorie-foods like pudding and feeding the baby in big quantities are erroneous approaches that result in obesity in children [23] [25].

On examining how many months an obese child has been breastfed, it has been found out that 15 (30\%) of obese children have been breastfed for $13-16$ months, 15 (30\%) of them for 17 - 24 months, 10 (20\%) of them 9 - 12 months, 2 (4\%) of them 1 - 4 months, 2 (4\%) of them 5 - 8 months and 6 (12\%) of them have never been breastfed. On examining how many months they have been breastfed without taking additional nutrition, it has been found out that 15 (30\%) of the children have been exclusively breastfed for 1 - 3 months, 15 (30\%) of them 4 months, 5 (10\%) of them 5 months, and $11(22 \%)$ of them 6 month. It can be said for this study that the period of receiving breastfeeding of the children and receiving exclusively breastfeeding is on a good level.

It has been found out that $23(46 \%)$ of the children have started to consume additional food with baby bottle, and 27 (54\%) of them with spoon. This is a finding suggesting training on the issue of feeding the child with a spoon instead of baby bottle when starting to give additional food. It has been found out that $30(60 \%)$ of the children have started to receive additional food with baby formula, $10(20 \%)$ of them with baby biscuits, 5 (10\%) of them with fruit-vegetable mash or fruit juice and $4(8 \%)$ of them with yoghurt, and $1(2 \%)$ of them with cow milk. It has been made known that starting to give additional food in an early period contributes to obesity prevalence and causes obesity in later ages. Sancak and colleagues observed in their studies (1999) that obese students had been breastfed for shorter periods than normal students. It is thought that the high calorie and fat contents of additional foods is effective in this sense [40].

On examining child's being fed with formula/baby bottle whenever he/she cries, 22 (44\%) of the children gets fed when they cry or get sick, and 28 (56\%) of them do not. It is seen that mothers and baby sitters should be trained about this.

It has been found that $19(38 \%)$ of the mothers had knowledge about starting additional foods, while 31 (62\%) of them did not; 9 (47.37\%) of the mothers who 
had knowledge about starting additional foods, 7 (36.85\%) of them have learnt it from doctor or a nurse, 1 (5.26\%) from TV, radio and such communication tools, and $2(10.52 \%)$ of them from newspapers and magazines. Additional foods should be added to the diet gradually so as to ensure shifting from breastfeeding to nutrition period with an adult type diet. Therefore mothers should be given detailed information about the time of additional foods and quality and quantity of the foods that baby should get. It is seen that the number of mothers who got information from communication tools as TV, radio is small. Nurses have undertaken rather important roles in giving such services.

While $10(20 \%)$ of the children eat 2 times or more, $25(50 \%)$ of them 3 or more, $12(24 \%)$ of them 4 or more, $3(6 \%)$ of them 5 or more, whereas it has been found that $41(82 \%)$ of the children eat between meal times (Table 2). It was seen that $32(64 \%)$ of the children get busy with some other work during meal time and 18 (56.25\%) of them enjoy watching TV, and $12(37.5 \%)$ of them like to play games. This is an important finding for mothers to pay attention to this fact while feeding their children.

Getting busy with some other thing during nutrition also leads the children's obesity. Because children continue to eat without perceiving that they are

Table 2. Distribution of some findings about the nutrition of the obese child.

\begin{tabular}{|c|c|c|}
\hline & $\mathrm{n}$ & $\%$ \\
\hline \multicolumn{3}{|c|}{ Number of daily meals of the children } \\
\hline 2 meals & 10 & 20.0 \\
\hline 3 meals & 25 & 50.0 \\
\hline 4 meals & 12 & 24.0 \\
\hline $5+\uparrow$ meals & 3 & 6.0 \\
\hline \multicolumn{3}{|l|}{ Snatching between meals } \\
\hline Yes & 41 & 82.0 \\
\hline No & 9 & 18.0 \\
\hline \multicolumn{3}{|c|}{ Dealing with another thing while eating } \\
\hline Deals & 32 & 64.0 \\
\hline Does not deal & 18 & 36.0 \\
\hline \multicolumn{3}{|c|}{ What does he enjoy while he is eating?* } \\
\hline Watching TV & 18 & 56.25 \\
\hline Playing games & 12 & 37.50 \\
\hline Listening to music & 2 & 6.25 \\
\hline \multicolumn{3}{|c|}{ What Are The Foods That The Child Likes Most } \\
\hline Pastry, pies, macaroni & 16 & 32.0 \\
\hline Soup and meals & 16 & 32.0 . \\
\hline Meals with meat & 7 & 14.0 \\
\hline Chocolate and desserts & 6 & 12.0 \\
\hline Breast milk & 4 & 8.0 \\
\hline Fried & 1 & 2.0 \\
\hline Total & 50 & 100.0 \\
\hline
\end{tabular}

${ }^{*} \mathrm{~N}$ value is different because this question was asked to children who deal with another thing while eating $(\mathrm{n}=50-18=32)$. 
already full if they are directing their attention to something else. This is an important factor for the development of obesity [15].

Some important findings regarding the feeding of children included in the study are shown in Table 2. It was found in study of Tuna and colleagues (2003) that 72 of children $(79.1 \%)$ ate at least 3 main meals, and 19 of children eat 2 main meals [18]. These findings show resemblance with this study.

It was found that 22 of children (44\%) watch TV $1-2$ hours, and 18 of them (36\%) watch TV 3 - 4 hours daily. When we look at child's daily playtime, it was found that 21 of them (42\%) played for 1 - 2 hours, 25 of them (50\%) played for 3 - 4 hours, 2 of them (4\%) for 5 - 6 hours, 2 of them (4\%) for 7 hours and more a day. In various surveys it is expressed that there is a close relationship between watching TV duration and obesity. But this could not be found in some works [36). In the study of Sancak and colleagues work (1999), the rate of watching TV more than 3 hours was $33.3 \%$ in obese children, while this rate was $8 \%$ in control group and the difference was found to be statically significant. It was seen that the obesity prevalence in students duration of watching TV was more than 3 hours a day was rather high [40]. It can be said that duration of watching TV is rather high in this study. Parents should be trained in that issue.

\section{4) Findings regarding the nutrition of parents with obese children}

Some findings reflecting the nutritional habits of the obese children are shown in Table 3.

It is seen that 27 (54\%) of parents eat fast (Table 3). Eating fast may cause too much food and energy consumption at a certain time. This is the utmost factor that prepares individuals for obesity [15]. Durukan (2001) found out in his research that eating rate of $42 \%$ of an obese group is slow while eating rate of $58 \%$ of them is fast [7]. This finding shows resemblance with this study.

It is found out that 26 (52\%) of parents of the children had worries about being obese but 24 (48\%) of them had no such worries. Alemdar (1995) found in his study that $51.5 \%$ of parents of the students worried about their children being obese [15]. This finding shows resemblance with this study.

Parents pointed out at the highest rate (58\%) that obesity is a factor that impairs health. The rate of the parents who do not know whether obesity is a factor that impairs health is $10 \%$.

It is found out that $34 \%$ of parents obtain information about obesity from means of communication tools, while $18 \%$ of them obtain from their parents or colleagues, and $6 \%$ of them obtain from dieticians or nurses. The rate of parents who did not learn anything about obesity is $42 \%$. The health staff should give importance to education of individuals about obesity that is the utmost threaten against health of our times.

Fifty-four percent of the parents have indicated that they wanted to get information about obesity while $46 \%$ of them pointed out that they do not want information about it. Eighty-two percent of the parents considered their children healthy. When we look at parent's definitions of good nutrition, we see that 3 
Table 3. Distribution of the findings reflecting the nutritional habits of the obese children.

\begin{tabular}{|c|c|c|}
\hline & $\mathrm{n}$ & $\%$ \\
\hline \multicolumn{3}{|l|}{ Daily meal figure } \\
\hline 2 meals & 19 & 38.0 \\
\hline 3 meals & 27 & 54.0 \\
\hline 4 meals & 3 & 6.0 \\
\hline $5+\uparrow$ meals & 1 & 2.0 \\
\hline \multicolumn{3}{|l|}{ Meal skipped generally } \\
\hline Breakfast & 9 & 18.0 \\
\hline Lunch & 12 & 24.0 \\
\hline I don’t skip & 29 & 58.0 \\
\hline \multicolumn{3}{|l|}{ Reason for skipping meals * } \\
\hline Since I don't want it & 11 & 52.4 \\
\hline Since I cannot find opportunity & 2 & 9.5 \\
\hline To lose weight & 1 & 4.8 \\
\hline Other & 7 & 33.3 \\
\hline \multicolumn{3}{|l|}{ Eating speed } \\
\hline Fast (15minutes or less) & 27 & 54.0 \\
\hline Middle & 14 & 28.0 \\
\hline Slow (30 min or more) & 9 & 18.0 \\
\hline \multicolumn{3}{|c|}{ The foods you consume most between meals. } \\
\hline Tea, coffee & 27 & 54.0 \\
\hline Cake, pastry, pies & 10 & 20.0 \\
\hline Fruit, fruit juices & 7 & 14.0 \\
\hline Dry fruit & 3 & 6.0 \\
\hline Candy, chocolate, ice cream & 2 & 4.0 \\
\hline I don't eat & 1 & 2.0 \\
\hline \multicolumn{3}{|l|}{ While eating I... with another thing } \\
\hline Deal with & 38 & 76.0 \\
\hline Don't deal with & 12 & 24.0 \\
\hline \multicolumn{3}{|l|}{ Occupation you do while eating ${ }^{* *}$} \\
\hline Watching TV & 28 & 73.69 \\
\hline Listening to music & 6 & 15.79 \\
\hline Reading book & 3 & 7.89 \\
\hline Reading newspaper & 1 & 2.63 \\
\hline \multicolumn{3}{|l|}{ Eating reasons } \\
\hline Since it is mealtime & 27 & 54.0 \\
\hline Since I'm hungry & 14 & 28.0 \\
\hline Since foods are attractive & 5 & 10.0 \\
\hline Since I'm repined & 4 & 8.0 \\
\hline
\end{tabular}




\section{Continued}

\begin{tabular}{ccc}
\hline Eating Times & & \\
Mealtime & 36 & 72.0 \\
Any time & 9 & 18.0 \\
In betweens & 3 & 6.0 \\
While preparing meal & 2 & 4.0 \\
Under which conditions you eat more? & & \\
When I'm sad & 26 & 52.0 \\
When I'm cheerful, excited & 11 & 22.0 \\
Does not change & 13 & 26.0 \\
What are the foods you consume much under such circumstances?* & & \\
Pies & 14 & 36.8 \\
Chocolate & 12 & 31.6 \\
Pastry & 7 & 18.4 \\
Coke/Drinks & 3 & 7.9 \\
Other (Bread, Appetizers) & 2 & 5.3 \\
Diet Food Consumption & & \\
Yes & & \\
No & 10 & 20.0 \\
Sometimes & 35 & 70.0 \\
Total & 5 & 10.0 \\
\hline
\end{tabular}

${ }^{*} \mathrm{~N}$ value is different because this question is asked to mothers who skip meals $(\mathrm{n}=50-29=21) .{ }^{*} \mathrm{~N}$ value is different because this question is asked to mothers who deal with another thing while eating $(\mathrm{n}=50-12$ $=38$ ).

(6\%) of them defined it as feeding with banana everyday, $9(18 \%)$ of them defined as feeding with the most expensive foods, 2 (4\%) of them defined as feeding with package food and 28 (56\%) of them defined as feeding with every kind of food in equal amounts. The amount of parents who give some other reasons like "I give a cup of milk everyday; I try to cook vegetable meals in two or three days a week" is $8(16 \%)$.

\section{5) Analysis of factors that may affect the child's nutrition and obesity}

Though there isn't any significant relation with the age of the obese child and the SDS value ( $\mathrm{p}>0.05)$, a significant relation with the RW value has been found $(\mathrm{p}<0.05)$ (Table 4).

There isn't any significant relation between the gender of obese children and the SDS value ( $p>0.05)$. It is found out that, boys have higher SDS and RW values numerically when compared to girls.

There isn't any statistically significant relation between the family types and the child's SDS and RW values ( $p>0.05)$. There isn't any statistically significant relation between the number of children in a family and the SDS value ( $p>$ $0.05)$. There isn't any statistically significant relation between the BMI values of parents and the SDS and RW values of children ( $\mathrm{p}>0.05)$. It is found that the BMI value of mother is higher than the 6 (13.95\%) children who are normal with values between 20 and 24 and the BMI value of mother is 2 or more over the SDS values of $7(16.28 \%)$ children who are obese. Though there isn't any statistically significant difference, the SDS and RW levels of children of mothers who 
Table 4. Analysis of children's Standard Deviation Score (SDS) and Relative Weight (RW) values according to age.

\begin{tabular}{|c|c|c|c|c|c|c|}
\hline \multirow{3}{*}{ Age } & \multicolumn{4}{|c|}{$\underline{\mathrm{SDS}}$} & \multirow{2}{*}{\multicolumn{2}{|c|}{$\underline{\text { Total }}$}} \\
\hline & \multicolumn{2}{|c|}{$\underline{1-2}$} & \multicolumn{2}{|c|}{2 and over } & & \\
\hline & $\underline{\mathrm{n}}$ & $\underline{\%^{*}}$ & $\underline{\mathrm{n}}$ & $\underline{\%^{*}}$ & $\underline{\mathrm{n}}$ & $\%^{* *}$ \\
\hline $14-20$ months & 8 & 16 & 7 & 14 & 15 & 30.0 \\
\hline $21-30$ months & 15 & 30 & 4 & 8 & 19 & 38.0 \\
\hline $31-36$ months & 10 & 20 & 6 & 12 & 16 & 32.0 \\
\hline \multirow[t]{3}{*}{ Total } & 33 & 66 & 17 & 34 & 50 & 100.0 \\
\hline & \multicolumn{5}{|c|}{$\begin{array}{l}{ }^{\star} \text { Percentage of Line }{ }^{* *} \text { Percentage of Column } \\
\qquad \mathrm{X}^{2}=2.579 \mathrm{p}=0.275 \mathrm{p}>0.05\end{array}$} & \\
\hline & \multicolumn{4}{|c|}{$\underline{\mathrm{RW}}$} & \multirow{2}{*}{\multicolumn{2}{|c|}{$\underline{\text { Total }}$}} \\
\hline \multirow{2}{*}{$\underline{\text { Age }}$} & \multicolumn{2}{|c|}{$\underline{90 \%-110 \%}$} & \multicolumn{2}{|c|}{$\underline{110 \% \text { and over }}$} & & \\
\hline & $\underline{\mathrm{n}}$ & $\underline{\%^{*}}$ & $\underline{\mathrm{n}}$ & $\underline{\%^{*}}$ & $\underline{\mathrm{n}}$ & $\underline{\%^{* *}}$ \\
\hline $14-20$ months & 2 & 4 & 13 & 26 & 15 & 30.0 \\
\hline $21-30$ months & 6 & 12 & 13 & 26 & 19 & 38.0 \\
\hline $31-36$ months & 10 & 20 & 6 & 12 & 16 & 32.0 \\
\hline Total & 18 & 36 & 32 & 64 & 50 & 100.0 \\
\hline
\end{tabular}

${ }^{\star}$ Percentage of Line; ${ }^{* *}$ Percentage of Column. $\chi^{2}=8.383 p=0.015 p<0.05$.

are obese with BMI values over 25 are numerically high.

There isn't any statistically significant relation between the SDS and RW levels of the child and the educational status of the father ( $p>0.05)$. There isn't any statistically significant relation between the SDS and RW levels of the child and the education background of the mother $(p>0.05)$. As the education background of mother improves, the SDS and RW values of the child decreases.

There isn't any statistically significant relation between the SDS and RW levels of the child and the socio-economic situation of parents ( $\mathrm{p}>0.05)$.

The fact that obesity is more common in lower socio-economic groups and overcrowded families in developed countries is related to the facts that in these groups the lack of information is common, there are less activities, foods with higher calorie levels are cheaper and the possibility of finding suitable food is limited and this diverts people to a single type of nutrition [7] [23] [25] [34].

Today, it is known that maternal factors in intrauterine period are effective in postnatal obesity. Though there isn't any statistically significant relation between the SDS and RW levels of the children and the nutrition of mother when pregnant ( $p>0.05$ ), it is found that the SDS and RW values of the children of mothers who had a good nutrition are higher. There is no statistically significant relation between the SDS and RW values of children and the weights that the mother gained when pregnant ( $p>0.05)$. It is found that the SDS values of $3(6.98 \%)$ children whose mother gained $7-10 \mathrm{~kg}$ when pregnant are 2 and over, and the SDS values of $10(23.25 \%)$ children whose mother gained $11 \mathrm{~kg}$ and over are 2 
and over.

In order to find out whether or not there is a difference between the SDS and RW values of the children and the weight gained by the mothers during pregnancy, independent inter-group $t$ test was used. According to the findings, it was seen that the difference between the weights that the mother gained when pregnant and the unclassified SDS data of the children is statistically insignificant ( $p>0.05)$, and the difference between the weights that the mother gained when pregnant and the unclassified RW data is statistically significant $(\mathrm{p}<0.05)$.

There isn't any statistically significant relation between the SDS and RW values of the child and the birth time of the obese child ( $p>0.05)$. When independent inter-group $t$ test is used, though the difference between the unclassified SDS data of the child and the birth time of the obese child isn't found statistically significant, the difference between RW data is found to be significant $(\mathrm{p}<0.05)$.

There isn't any statistically significant relation with the SDS and RW values of the child and the birth weight of the obese child ( $p>0.05)$. While the SDS values of $5(10 \%)$ children with a birth weight of $2-3.5 \mathrm{~kg}$ are 2 or over, the SDS values of $8(16 \%)$ children with a birth weight of $3.6 \mathrm{~kg}$ and over are 2 or over. While the RW value of 11 (22\%) children with a birth weight of $2-3.5 \mathrm{~kg}$ are $110 \%$ or over, the RW values of 16 (32\%) children with a birth weight of $3.6 \mathrm{~kg}$ and over are $110 \%$ or over. The risk of developing obesity in childhood and adolescence period of children who have a high birth weight has increased. Tuna and colleagues (2003) analyzed the effect of birth weight on relative weight in their study and found out that the RW value of the group with a high birth weight is significantly higher when compared to both the group with a low birth weight and the group with a normal birth weight [18]. Aktaş (2001) found out a positive correlation between the BMI levels of male and female students who have a BMI level higher than 23 and their birth weights in his study [17]. There is a resemblance with the fact that the SDS and RW values of the obese children with a high birth weight are higher when compared to the children with a low birth weight.

There isn't any statistically significant relationship between the SDS and RW values of the child and the period he consumed breast milk ( $\mathrm{p}>0.05)$. While the SDS value of 4 (8\%) children who consumed breast milk for $1-8$ months are 2 and over, the SDS values of $9(18 \%)$ children who consumed breast milk for 9 - 24 months are 2 and over. Tuna and colleagues (2003) found out that there isn't any difference between the breast milk consumption period and the time in which additional nutrients began to be consumed between the obese group and the controlled group in their study [18].

Variance analysis was used in order to find out whether there is a difference between the SDS and RW values of the children and the period she/he was breastfed, and the difference was found to be statistically significant $(\mathrm{p}<0.05)$.

Correlation analysis was carried out in order to find the direction and power of the relation between the SDS and RW values of the children and the period 
they were breastfed.

There isn't any positive directional but statistically significant relation between the period in which the child was breastfed and the SDS value $(r=0.133 ; p$ $=0.356)$. There isn't any negative directional but statistically significant relation between the period in which the child consumed breast milk and the RW value $(\mathrm{r}=0.189 ; \mathrm{p}=0.190)$.

There isn't any statistically significant relation with the nutrition group which the child began to consume as additional food and the SDS and RW values ( $p$ > $0.05)$. While the SDS value of $6(12 \%)$ children who began additional food with baby biscuits, fruit and vegetable mash or juice are 2 and over, the SDS value of 11 (22\%) children who began additional food with infant formula are 2 and over. While the RW value of 12 (24\%) children who began additional food with baby biscuits, fruit and vegetable mash or juice are $110 \%$ and over, the RW value of 20 (40\%) children who began additional food with infant formula are $110 \%$ and over. The SDS and RW values of children who began additional food with infant formula are numerically higher when compared to children who began additional food with baby biscuits, fruit and vegetable mash or juice etc.

Independent inter-group $t$ test was used in order to find out whether there is a difference between the nutrient group which the child consumed as additional food and the SDS and RW values, but the difference isn't found statistically significant $(\mathrm{p}>0.05)$. There isn't any statistically significant relation with the number of meals that the child eats and the SDS and RW values $(\mathrm{p}>0.05)$.

There isn't any statistically significant relation between the time spent for eating meals of parents and the SDS and RW values of children ( $p>0.05)$. Independent inter-group $t$ test was used in order to find out whether there is a difference between the meal length of parents and the SDS and RW values of children, but the difference isn't found to be statistically significant ( $p>0.05)$.

There isn't any statistically significant relation between the time the child watches TV and the SDS and RW values ( $p>0.05$ ). While the SDS value of 9 (18\%) children who watch TV for $1-2$ hours a day are found 2 and over, the SDS value of $6(12 \%)$ children who watch TV for 3 - 6 hours a day are found 2 and over. While the RW value of 16 (32\%) children who watch TV for 1 - 2 hours a day are found $110 \%$ and over, the RW value of 10 (20\%) children who watch TV for 3 - 6 hours a day are found 2 and over. Tuna and colleagues (2003) found that the time the obese group spends watching TV or computer and activity time was significantly higher when compared to the control group [18].

Variance analysis was used in order to find out whether there was a difference between the time a child spends watching TV a day and the SDS and RW values. The difference between the time a child spends watching TV a day and the unclassified SDS and RW data of the child isn't found statistically significant ( $\mathrm{p}>$ 0.05).

Correlation analysis was carried out in order to find the direction and strength of the relation between the time an obese child watches TV a day and the SDS 
and RW values of the child. There isn't any positive relation that was statistically significant between the time an obese child watches TV a day and the SDS value $(\mathrm{r}=0.044 ; \mathrm{p}=0.761)$.

There isn't any negative directional but statistically significant relation between the time an obese child watches TV a day and the RW value $(r=-0.138 ; p$ $=0.340$ ).

Though there isn't any statistically significant relation between the play hours of the child and the SDS value ( $\mathrm{p}>0.05$ ), a significant relation with the RW value is found ( $\mathrm{p}<0.05)$ (Table 5).

Correlation analysis is carried out in order to find the direction and strength of the relation between the daily play hours of an obese child and the SDS and RW values. There is positive relation that was statistically significant between the daily play hours of an obese child and the SDS value $(r=0.629 ; p=0.000)$. There isn't any positive relation that was statistically significant between the daily play hours of an obese child and the RW value $(r=-0.21 ; \mathrm{p}=0.143)$.

\subsection{Conclusions}

It is realized that most of the studies carried out about obesity is mostly about children of the adolescence period or the school age. The study is carried out in the provincial centre of Konya which is in Central Anatolia Region of Turkey, where nutrition with mostly carbohydrate foods is traditional and where healthy child means a sturdy child. With the finding that $82 \%$ of the parents consider their children as healthy, it is concluded that first of all, the healthy child image of families should be changed.

The first place about childhood obesity is the family environment. As regular

Table 5. Analysis of Standard Deviation Score (SDS) and Relative Weight (RW) values According to Play Hours of the Child in a Day.

\begin{tabular}{|c|c|c|c|c|c|c|}
\hline \multirow{3}{*}{$\frac{\text { Play Hours of }}{\underline{\text { Child }}}$} & \multicolumn{4}{|c|}{$\underline{\text { SDS }}$} & \multirow{2}{*}{\multicolumn{2}{|c|}{ Total }} \\
\hline & \multicolumn{2}{|c|}{$1-2$} & \multicolumn{2}{|c|}{2 and Over } & & \\
\hline & $\underline{\mathrm{n}}$ & $\%^{*}$ & $\underline{\mathrm{n}}$ & $\underline{\%}$ & $\underline{\mathrm{n}}$ & $\underline{\%^{* *}}$ \\
\hline 1 - 2 Hours & 15 & 30 & 6 & 12 & 21 & 42.0 \\
\hline $3 \uparrow$ Hours & 18 & 36 & 11 & 22 & 29 & 58.0 \\
\hline \multirow[t]{3}{*}{ Total } & 33 & 66 & 17 & 34 & 50 & 100.0 \\
\hline & \multicolumn{4}{|c|}{$\begin{array}{c}{ }^{\star} \text { Line Percentage }{ }^{* *} \text { Column Percentage } \\
\mathrm{X}^{2}=0.150 \mathrm{p}=0.699 \mathrm{p}>0.05\end{array}$} & & \\
\hline & \multicolumn{4}{|c|}{$\underline{\mathrm{RW}}$} & & \\
\hline \multirow{2}{*}{$\frac{\text { Play Hours of }}{\text { Child }}$} & \multicolumn{2}{|c|}{$\underline{90 \%-110 \%}$} & \multicolumn{2}{|c|}{$\underline{110 \%}$ and Over } & \multicolumn{2}{|c|}{ Total } \\
\hline & $\underline{\mathrm{n}}$ & $\underline{\%^{*}}$ & $\underline{\mathrm{n}}$ & $\underline{\%^{*}}$ & $\underline{\mathrm{n}}$ & $\%^{* *}$ \\
\hline 1 - 2 Hours & 4 & 8 & 17 & 34 & 21 & 42.0 \\
\hline $3 \uparrow$ Hours & 14 & 28 & 15 & 30 & 29 & 58.0 \\
\hline Total & 18 & 36 & 32 & 64 & 50 & 100.0 \\
\hline
\end{tabular}

${ }^{\star}$ Line Percentage ${ }^{\star *}$ Column Percentage. $\chi^{2}=4.516 \mathrm{p}=0.034 \mathrm{p}<0.05$. 
nutritional habits of younger children are managed by parents or caregivers, they play an important role. Family based approach and a holistic health view are important in pediatric nursing. Also, the toddler period is the period in which many habits are acquired. For this reason, the study is carried out in order to find out the socio-demographic features of $1-3$ aged (play infant) obese children and their parents.

There isn't a statistically significant relation between the education background of mother, socio-economic level, family type, the number of children in a family and the SDS and RW values of the child ( $\mathrm{p}>0.05$ ). There isn't any statistically significant relation between the period the obese child consumed breast milk, the number of meals the child eats, the length of meal of parents and the SDS and RW values of the child. There isn't any statistically significant relation between the time the child spends watching TV and the SDS and RW values of the child ( $p>0.05)$. Though there isn't any statistically significant relation between the play hours of the child and the SDS value ( $p>0.05$ ), a significant relation with the RW value is found $(\mathrm{p}<0.05)$.

A statistically significant difference between the weight the mother gained during pregnancy, the time of birth and the unclassified RW data of the child is found $(\mathrm{p}<0.05)$. Variance analysis is carried out in order to find out whether there is a difference between the period in which the child consumed breast milk and the SDS and RW values of the child and the difference is found statistically significant $(\mathrm{p}<0.05)$.

\section{Practical Implications}

As the difference between the weight the mother gained when pregnant and the unclassified RW data of the child is found statistically significant, it is necessary to provide education during pregnancy about healthy nutrition. As the difference between the time the child spends consuming breast milk and the SDS and RW values of the child is significant, it is fairly important that babies are fed with breast milk only for the first 6 months and after 6th month additional food should be given to babies along with breast milk. It is also important that pediatric nurses instruct families about passing from breast milk to additional food.

Nutrition is an utmost factor in a child's health. What kinds of nutrition groups of food are consumed and their amount are important in a child's physical, cognitive and emotional growth and development.

During the first two years after birth, the nutrition needs of newborn and children of toddler period change rapidly, and shift from breastfeeding only to menus that include vegetables, fruits, cereal and solid food. Nutrition practices in baby hood are really important for growth and development and it may affect the eating habits and choices in late childhood periods.

In toddler period, the child consumes what she/he is given. Parents and caretakers should be aware of the fact that their own nutrition habits and the food they like and don't like will be imitated by the child. The nutrition experiences of 
childhood have important effects on nutrition habits of adulthood. For this reason, the child should be familiarized with different kinds of food without obligation, and by this way, obtaining a healthy food choice habit in adulthood should be aimed at. Healthy nutrition advices can target the entire family, but the fact that small children need special nutrients must be taken into consideration.

In the study, it is found that the time the group of $1-3$ aged obese children spends watching TV is found to be rather great. It is necessary to train families and caregivers about this matter. As there is a significant relation between the daily play hours of the child and the RW value, it important for parents to spend more time playing with their children and to increase the play hours. In order to prevent obesity, it is advised that the area of play and play activities of children should be increased. The risks of obesity should be considered in children in toddler period and the rate of obesity should be decreased especially at these ages.

In conclusion, the families should be made aware of the factors that cause obesity in children in toddler period. With this purpose, making use of literature for toddler period obesity, informing booklets have been prepared and given to parents so as to help inform them.

\section{Acknowledgements}

This research received financial support from Selcuk University Research Fund.

\section{References}

[1] Şarbat, G. and Demirkol, M. (1999) Obesity. In: Ekşi, A., Ed., I Am Not Ill, Nobel Medicine Bookstore, Ankara, 441-450. (In Turkish)

[2] Cinaz, P. and Bideci, A. (2003) Obesity. In: Günöz, H., Öcal, G., Yordam, N. and Kurtoğlu, S., Eds., Pediatric Endocrinology, 1st Edition, Pediatric Endocrinology and Oxology Association Publications, Ankara, 487-505. (In Turkish)

[3] Troiano, R.P., Flegal, K.M., Kuczmarski, R.J., Campbell, S.M. and Johnson, C.L. (1995) Overweight Prevalence and Trends for Children and Adolescents. The National Health and Nutrition Examination Surveys, 1963 to 1991. Archives of Pediatrics \& Adolescent Medicine, 149, 1085-1091. https://doi.org/10.1001/archpedi.1995.02170230039005

[4] Karakaş, S., Okyay, P., Önen, Ö., Ergin, F.A. and Beşer, E. (2002) Aydın Country Urban and Rural Area Primary Education Schools 7 - 14 Age Group Students' Body Mass Index, 8. Department of Public Health, Dicle University, Diyarbakır, 741-748. (In Turkish)

[5] Esmailzadeh, L. (1994) Obesity Prevelance and the Factors that Effects of Students Having Different Socio-Economics Degree in Ankara. Home Economy Main Science Master Thesis, Ankara University, Unpublished. (In Turkish)

[6] Özçirpici, B., Şahinöz, S., Özgür, S. and Bozkurt, A.I. (2004) Obesity Prevalence in Gaziantep Province, IX. In: Public Health Congress Bulletin Abstract Book, Publishing House, Ankara, 37. (In Turkish)

[7] Durukan, P. (2001) The Valuation of Affect of Obesity Factors on Physical Activity and Physio-Social Factors. Expertness Thesis, Ankara University, Ankara. (In Turkish) 
[8] Arslan, P. (2003) The Principles of Diet Treatment of Childhood and Adolescent. Turkish Journal of Endocrinology and Metabolism, 27-32. (In Turkish)

[9] Epik, G., Vitrinel, A., Kılıç, Ö., Cömert, S., Ağzıkuru, T., Erdağ, Ç. and Akin, Y. (2004) The Evaluation of Body Mass Index Measurement Results at the Ages of 2 -1 2 in Child Period. Child Forum, May-August 2004, 35-42. (In Turkish)

[10] Dietz, W.H. and Robinson, T.N. (1993) Assessment and Treatment of Childhood Obesity. Pediatrics in Review, 14, 337-344. https://doi.org/10.1542/pir.14-9-337

[11] Jain, A., Sherman, S.N., Chamberlin, L.A., Carter, Y., Powers, S.W. and Whitaker, R.C. (2001) Why Don't Low-Income Mothers Worry about Their Preschoolers Being Overweight? Pediatrics, 107, 1138-1146. https://doi.org/10.1542/peds.107.5.1138

[12] Drohan, S.H. (2002) Managing Early Childhood Obesity in the Primary Care Setting: A Behavior Modification Approach. Pediatric Nursing, 28, 599-610.

[13] Üstün, M. and Üstün, S. (1994) Hacettepe Lecture Notes. 5th Edition, Şencay Medical Publisher, Ankara, 533-534. (In Turkish)

[14] Köksal, G. and Gökmen, H. (2002) The Treatment of Nutrition in Child Diseases. 1st Edition, Hatipoğlu Publisher, Ankara, 135. (In Turkish)

[15] Alemdar, G. (1995) The Attitude and Behaviours about Obesity of Middle School Students. Master Thesis, Gazi University, Ankara. (In Turkish)

[16] Williams, C.L., Campanaro, L.A., Squillace, M. and Bollella, M. (1997) Management of Childhood Obesity in Pediatric Practice. Annals of the New York Academy of Sciences, 817, 225-240. https://doi.org/10.1111/j.1749-6632.1997.tb48209.x

[17] Aktaş, N. (2001) Obesity Prevalence and Which Consideration of Different Socio-Economic Degree That 9 - 11 Age Group Students in Konya Province Central. Doctorate Thesis, University, Ankara. (In Turkish)

[18] Tuna, C., Şıklar, Z., Ünsal, R. and Dallar, Y. (2003) The Evaluated of Risk Factors in Obese Children. The Journal of Pediatrics, 12, 169-175. (In Turkish)

[19] Erge, S. (2003) The Behavioral Treatment of Diet Treatment That Nourish in Obesity. Turkish Journal of Endocrinology and Metabolism, 2, 75-82. (In Turkish)

[20] Zeybek, Ç. and Aydın, A. (2002) Obesity in Childhood. Clinic Child Forum, Istanbul, 24-29. (Turkish)

[21] Arslan, P. (2004) Children and Adolescent Obesity and Principles of Medical Nutrition Treatment. Clinic Child Forum, Istanbul, November-December 2004, 6-11. (In Turkish)

[22] Yanovski, J.A. (2001) Pediatric Obesity. Reviews in Endocrine \& Metabolic Disorders, 2, 371-383. https://doi.org/10.1023/A:1011800532068

[23] Yiğit, H., Ertekin, V. and Altınkaynak, S. (2002) Obesity in Childhood. Syndrome, 14, 66-73. (In Turkish)

[24] Bundak, R., Neyzi, O., Günöz, H. and Darendeliler, F. (2002) Growth-Development and Disorders. In: Neyzi, O. and Ertuğrul, T., Eds., Pediatrics, 3th Edition, Nobel Medicine Bookstore, Ankara, 97-98. (In Turkish)

[25] Günöz, H., Saka, N., Darendeliler, F. and Bundak, R. (2003) Growth-Development and Endocrine. In: Cantez, T., Child Health and Illness, Nobel Medicine Bookstore, İstanbul, 111-114. (In Turkish)

[26] Tershakovec, A.M. and Stallings, V.A. (2001) Nutrition and Disorders in Child. In: Behrman, R.E., Kliegmen, R.M., et al., Eds., Nelson Essentials of Pediatrics, Nobel Medicine Bookstore, Ankara, 65-66. (In Turkish)

[27] Baysal, A. (2002) Nutrition. 9th Edition, Hatiboğlu Publisher, Ankara, 491. (In Tur- 
kish)

[28] Bulduk, S. (2002) Nutrition Principle and Menu Planning. 1st Edition, Detay Publisher, Ankara, 161-187. (In Turkish)

[29] Gökçay, G. and Garipağaoğlu, M. (2002) Nutrition in Childhood and Adolescent. 1st Edition, Saga Publisher, İstanbul, 94-104. (In Turkish)

[30] Demirci, M. (2003) Nutrition. 1st Edition, Rebel Publisher, İstanbul, 189-196. (In Turkish)

[31] Kavas, A. (2003) Right Nutrition. 3rd Edition, Literature Publisher, İstanbul, 186-201. (In Turkish)

[32] Altuğ, R. (2004) Nutrition in Infant and Childhood. 4th Edition, Bilge Culture Art Publication, İstanbul, 187-194. (In Turkish)

[33] Barlow, S.E. and Dietz, W.H. (1998) Obesity Evaluation and Treatment: Expert Committee Recommendations. Pediatrics, 102, 1-11. https://doi.org/10.1542/peds.102.3.e29

[34] Özenoğlu, A., Sabuncu, T. and Ünüvar, E. (2000) Exogen Obesity That Adolescent Keep to Energy and Food Element Distribution in Daily Diet. Gravitate to Endocrinology, 9, 38-43. (In Turkish)

[35] Dündar, Y., Evliyaoğlu, O. and Hatun, Ş. (2000) Length Shortness and Obesity in School Children: Neglect Is a Problem. Clinical Pediatrics, 9, 19-22.

[36] Fogelholm, M., Nuutinen, O., Pasanen, M., Myöhönen, E. and Saatela, T. (1999) Parent-Child Relationship of Physical Activity Patterns and Obesity. International Journal of Obesity and Related Metabolic Disorders, 23, 1262-1268. https://doi.org/10.1038/sj.ijo.0801061

[37] Toksoy, H., Kafali, G., Kaya, R. and Gültekin, A. (1994) Obesity Prevalence That School Students in Sivas Region. Cumhuriyet Medical Journal, 16, 137-141. (In Turkish)

[38] Dietz, W.H. (1994) Critical Periods in Childhood for the Development of Obesity. The American Journal of Clinical Nutrition, 59, 955-959. https://doi.org/10.1093/ajcn/59.5.955

[39] Darcan, Ş., Çoker, M., Can, Ş. and Gökşen, D. (2000) The Role of Family and Environmental Factors in Evolution of Childhood Exogen Obesity. Ege Pediatry Bulletin, 7, 73-76. (In Turkish)

[40] Sancak, R., Dündar, C., Totan, M., Çakir, M., Sunter, T. and Küçüködük, Ş. (1999) Obesity Prevalence and Predisposing Factors in Middle School and High School students. Nineteen May University Medicine Journal, 16, 19-24. 